\title{
Effects of morphine on histamine release from two cell lines of canine mast cell tumor and on plasma histamine concentrations in dogs with cutaneous mast cell tumor
}

\author{
Taylor L. Curley DVM \\ Douglas H. Thamm VMD \\ Sam W. Johnson DVM \\ Pedro Boscan DVM, PhD
}

From the Department of Clinical Sciences, Colorado State University, Fort Collins, CO 8052I.

Address correspondence to Dr. Boscan (pboscan@ colostate.edu).

\begin{abstract}
OBJECTIVE
To determine the effects of morphine on histamine release from 2 canine mast cell tumor (MCT) cell lines and on plasma histamine concentrations in dogs with cutaneous MCTs.
\end{abstract}

\section{ANIMALS}

10 dogs with cutaneous MCT and 10 dogs with soft tissue sarcoma (STS).

\section{PROCEDURES}

The study consisted of 2 phases. First, 2 canine MCT cell lines were exposed to 3 pharmacologically relevant morphine concentrations, and histamine concentrations were determined by an ELISA. Second, dogs with MCT or STS received $0.5 \mathrm{mg}$ of morphine $/ \mathrm{kg}$, IM, before surgery for tumor excision. Clinical signs, respiratory rate, heart rate, arterial blood pressure, rectal temperature, and plasma histamine concentrations were recorded before and $5,15,30$, and 60 minutes after morphine administration but prior to surgery. Data were compared by use of a 2-way ANOVA with the Sidak multiple comparisons test.

\section{RESULTS}

In the first phase, canine MCT cell lines did not release histamine when exposed to pharmacologically relevant morphine concentrations. In the second phase, no differences were noted for heart rate, arterial blood pressure, and rectal temperature between MCT and STS groups. Plasma histamine concentrations did not significantly differ over time within groups and between groups.

\section{CONCLUSIONS AND CLINICAL RELEVANCE}

No significant changes in histamine concentrations were noted for both in vitro and in vivo study phases, and no hemodynamic changes were noted for the in vivo study phase. These preliminary results suggested that morphine may be used safely in some dogs with MCT.
M ast cell tumors (MCTs) are the most common cutaneous neoplasia reported in dogs. ${ }^{1,2}$ Opioids are often administered for analgesia as part of the anesthesia protocol for MCT excision. ${ }^{3,4}$ Opioids such as morphine can help reduce anesthesia requirements ${ }^{5,6}$ and provide postsurgical analgesia.,8 Morphine among some other opioids can induce the release of histamine, tryptase, prostaglandins, and heparin from circulating and cutaneous mast cells. ${ }^{9-11}$ Therefore, at least anecdotally, veterinarians have been reluctant to include morphine as part of an anesthesia protocol for MCT excision; yet, no data that support their reluctance have been published.

Morphine-induced histamine release from mast cells does not appear to be mediated through agonism of opioid receptors on mast cells or through the plasma concentration of morphine.,11 Thus, the mechanism of action for morphine-induced histamine release from mast cells is unknown. Also, determining the safety of morphine use during general anesthesia for MCT excision is important because histamine and other cytokines may induce vasodilation, systemic hypotension, airway edema, broncho- spasm, and diarrhea. The possible development of these reactions, commonly described as anaphylactic or anaphylactoid-like reactions, increases anesthetic risk. Therefore, the objective of the study reported here was to determine the effect of morphine on histamine release from 2 cell lines of canine MCT and on plasma histamine concentrations in dogs with cutaneous MCTs. The study hypotheses were that morphine will induce histamine release from these cell lines and increase plasma histamine concentrations in dogs with cutaneous MCTs.

\section{Materials and Methods}

\section{Cell lines and conditions}

Two canine MCT cell lines, C2 and BR, were maintained in C10 media (RPMI 1640 culture medium [Lonza Group Ltd] supplemented with heat-inactivated $10 \%$ fetal bovine serum [Peak Serum Inc] and a solution mixture [Cellgro] of $1 \mathrm{X}$ minimum essential medium, $2 \mathrm{mM}$ L-glutamine, $1 \mathrm{mM}$ sodium pyruvate, $1 \mathrm{X}$ nonessential amino acid solution, and $1 \mathrm{X}$ antimicrobial [bacteria and fungi] solution) and placed in a 
humidified incubator with $5 \% \mathrm{CO}_{2}$ at $37^{\circ} \mathrm{C}$. Cell lines were confirmed to be of canine origin by use of a multispecies multiplex PCR assay and authenticated with short-tandem repeated analysis as described. ${ }^{12}$ The $2 \times 10^{6} \mathrm{C} 2$ or BR cells were placed in $500 \mu \mathrm{L}$ of Tyrode buffer (Sigma-Aldrich) and incubated for 1 hour at $37^{\circ} \mathrm{C}$ in the presence of 1,100 , or $1,000 \mathrm{ng}$ of morphine/mL in duplicate. Mastoparan (Cayman Chemical; $25 \mu \mathrm{M}$ ) served as the positive control, and Tyrode buffer alone (untreated) served as the negative control. After incubation, the reactions were stopped with 15-minute incubation on ice, after which the supernatants were removed and stored at $-80{ }^{\circ} \mathrm{C}$ until analysis. Samples were thawed, and histamine concentrations were measured in duplicate by use of an ELISA (Immunotech). The assay's sensitivity was 0.05 $\mathrm{ng} / \mathrm{mL}$ and had been validated for histamine determination in dogs. ${ }^{13-15}$

\section{Clinical trial}

Written informed consent by dog owners was obtained for all dogs included in the study, and the Colorado State University Institutional Animal Care and Use Committee and Veterinary Teaching Hospital Clinical Review Board approved the study. Inclusion criteria were a confirmed diagnosis of MCT or soft tissue sarcoma (STS) via microscopic examination of cells collected through a fine-needle aspirate (cytology) or of tissue collected through a biopsy (histology), presentation for MCT or STS excision, > 1 year of age, and medical stability based on history, physical examination, $\mathrm{CBC}$, and serum biochemical analyses. Exclusion criteria were dogs that had a history of hypersensitivity reactions including those to food and environmental allergens, were pregnant, were presented for an emergency situation, had a history of respiratory or cardiovascular failure, had current or recent corticosteroid treatment $(<72$ hours before presentation), had chemotherapy in the week before presentation, or had been administered antihistamine drugs $(\mathrm{H} 1$ and $\mathrm{H} 2$ receptor antagonists) within the previous 3 days. To achieve a study power of $80 \%, 10$ dogs each from the MCT and STS groups were required to identify changes in plasma histamine concentration of $0.5 \mathrm{ng} / \mathrm{mL}$ with an $\alpha$ of $0.05 .^{15,16,17}$ Ten dogs with confirmed cutaneous MCT and 10 dogs with confirmed STS were included in the clinical trial.

All dogs were premedicated with $0.5 \mathrm{mg}$ of morphine/kg IM. A 20- or 22-gauge catheter (Becton, Dickinson and Co) was placed. Anesthesia was induced with propofol ( 2 to $8 \mathrm{mg} / \mathrm{kg}$, IV), to effect and was maintained with isoflurane. Acepromazine was avoided because of its antihistamine effects. ${ }^{18}$ Respiratory rate, heart (pulse) rate, blood pressure, rectal temperature, incidence of emesis, plasma histamine concentration, and any other observed abnormality (eg, arrhythmia, diarrhea, or behavior change) were recorded before and 5, 15, 30 , and 60 minutes after morphine administration but prior to surgery. Respiratory rate was determined by observing chest excursions, heart (pulse) rate was determined with palpation of the femoral pulse, noninvasive arterial blood pressure was obtained with an oscillometric blood pressure monitor (VetTRENDS), and rectal temperature was obtained with a thermometer (DTR-1221A; iProven). Plasma histamine concentrations were measured from $3 \mathrm{~mL}$ of blood collected from a cephalic or saphenous vein catheter. Blood samples were collected in glass tubes containing EDTA (BD Vacutainer; Becton, Dickinson and Co), and refrigerated immediately after collection until centrifugation (1,500 $X g$ for 15 minutes at $4{ }^{\circ} \mathrm{C}$ ). Plasma was stored at $-80{ }^{\circ} \mathrm{C}$ until analysis with an ELISA (LDN).

\section{Statistical analysis}

In vitro plasma histamine concentrations were compared among conditions (1, 100, and 1,000 ng of morphine/mL, positive control, and negative control) by use of an ANOVA with the Tukey post hoc test. In vivo patient variables (age, sex, and body weight) were reported and compared by use of descriptive statistics. Group data were analyzed for distribution normality with the Shapiro-Wilk test. Normally distributed data are presented as mean $\pm \mathrm{SD}$, and nonnormally distributed data are presented as median and range. Data between groups (MCT vs STS) were compared by use of a 2-way ANOVA followed by the Sidak multiple comparison test. Continuous variables were compared by use of a 1-way or 2-way ANOVA and then with the Tukey post hoc test. Statistical analyses were performed with commercial software (Prism version 9; GraphPad Software Inc). Values of $P<0.05$ were considered significant.

\section{Results}

\section{Cell lines and conditions}

After both canine MCT cell lines were exposed to morphine, histamine concentrations did not significantly $(P=0.48$ for $\mathrm{BR}$ cell line and $P=0.76$ for C2 cell line) differ from histamine concentrations for the untreated (negative control) cell lines (Figure I).

\section{Clinical trial}

Intramuscular administration of morphine resulted in a significant $(P<0.05)$ decrease in heart (pulse) rate and rectal temperature over time, compared with baseline (before morphine administration), in MCT and STS groups (Figures $\mathbf{2}$ and $\mathbf{3}$ ). No consistent significant changes in arterial blood pressure were observed, although systolic and diastolic arterial blood pressure decreased over time (Figure 4). All 10 dogs in the STS group and 9 of 10 dogs in the MCT group were panting before morphine administration. After morphine administration, 9 and 8 dogs in STS and MCT groups, respectively, continued to pant. Hemodynamic parameters remained within the expected values for normal dogs. When data were compared 


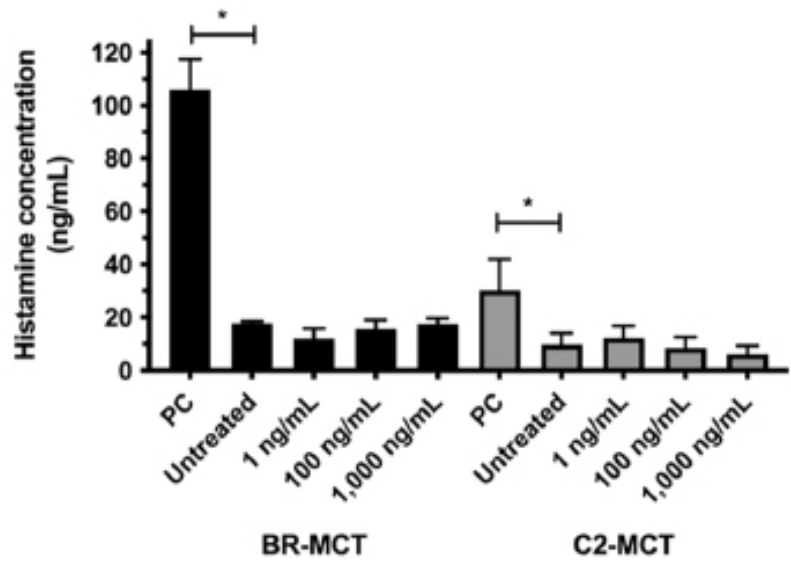

Figure I-In vitro supernatant histamine concentrations from canine BR- and C2-mast cell tumor (MCT) cell lines after exposure to I, 100 , or $\mathrm{I}, 000 \mathrm{ng}$ of morphine $/ \mathrm{mL}, 25 \mu \mathrm{M}$ mastoparan (positive control [PC]), or Tyrode buffer (negative control; untreated). *Indicates $P<0.05$ for comparison between PC and untreated cells.

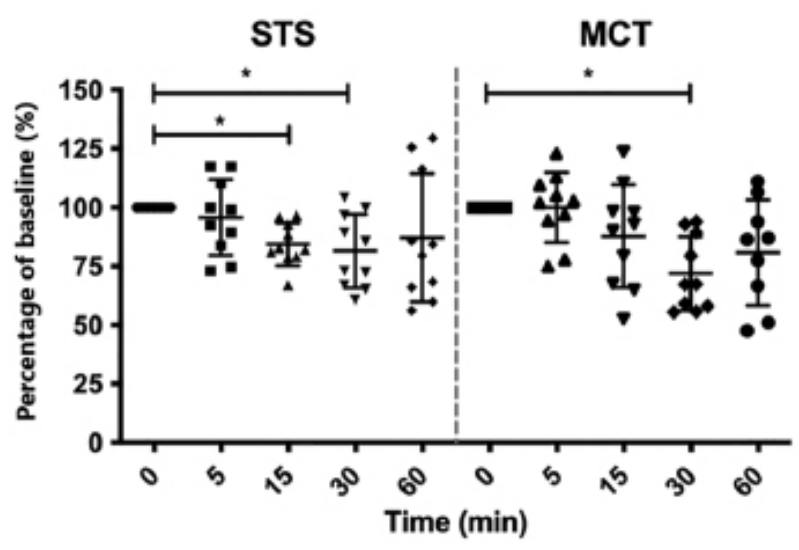

Figure 2-Changes in heart (pulse) rate (percentage of baseline, with baseline considered as 100\%) from time 0 (before morphine administration) and $5,15,30$, and 60 minutes after morphine administration $(0.5 \mathrm{mg} / \mathrm{kg}, \mathrm{IM})$ but prior to surgery for 10 dogs with MCT and 10 dogs with soft tissue sarcoma (STS). For each time point after morphine administration, mean (middle line) and SD (whiskers) are shown. *Indicates $P$ $<0.05$ between time points within each group.

between groups, no significant differences in heart rate $(P=0.62)$, rectal temperature $(P=0.87)$, or systolic $(P=0.19)$ and diastolic arterial blood pressure $(P$ $=0.21$ ) were observed over time. Morphine induced emesis in 6 dogs in the STS group and 3 dogs in the MCT group.

The median (range) plasma histamine concentrations at baseline (before morphine administration) were $0.75 \mathrm{ng} / \mathrm{mL}(0.2$ to $3.3 \mathrm{ng} / \mathrm{mL})$ and $0.4 \mathrm{ng} / \mathrm{mL}(0$ to $1.0 \mathrm{ng} / \mathrm{mL}$ ) for STS and MCT groups, respectively, and did not significantly differ $(P=0.10)$ between groups (Figure 5). Morphine did not significantly affect histamine concentrations over time within each group ( $P=0.76$ for STS; $P=0.67$ for MCT) and between groups $(P=0.76$; Figure 6). Dogs in the MCT group were more likely to experience a 3 -fold in-

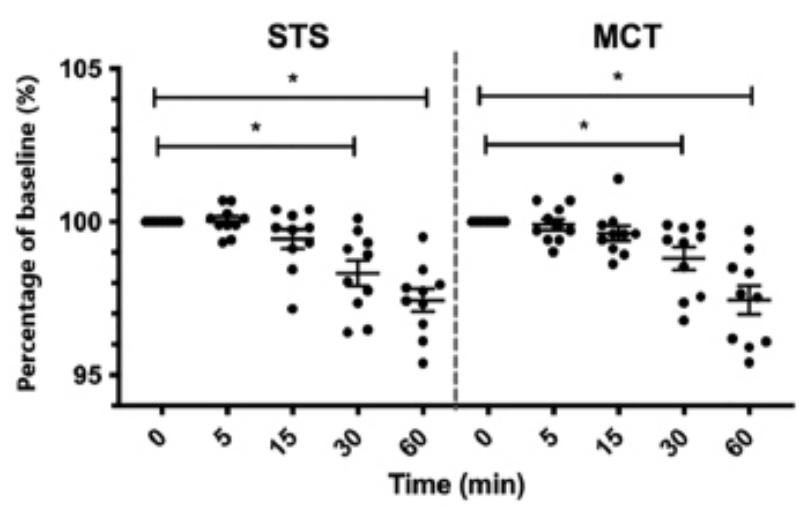

Figure 3-Changes in rectal temperature (percentage of baseline, with baseline considered as 100\%) from time 0 (before morphine administration) and 5, 15, 30, and 60 minutes after morphine administration but prior to surgery. See Figure 2 for key.
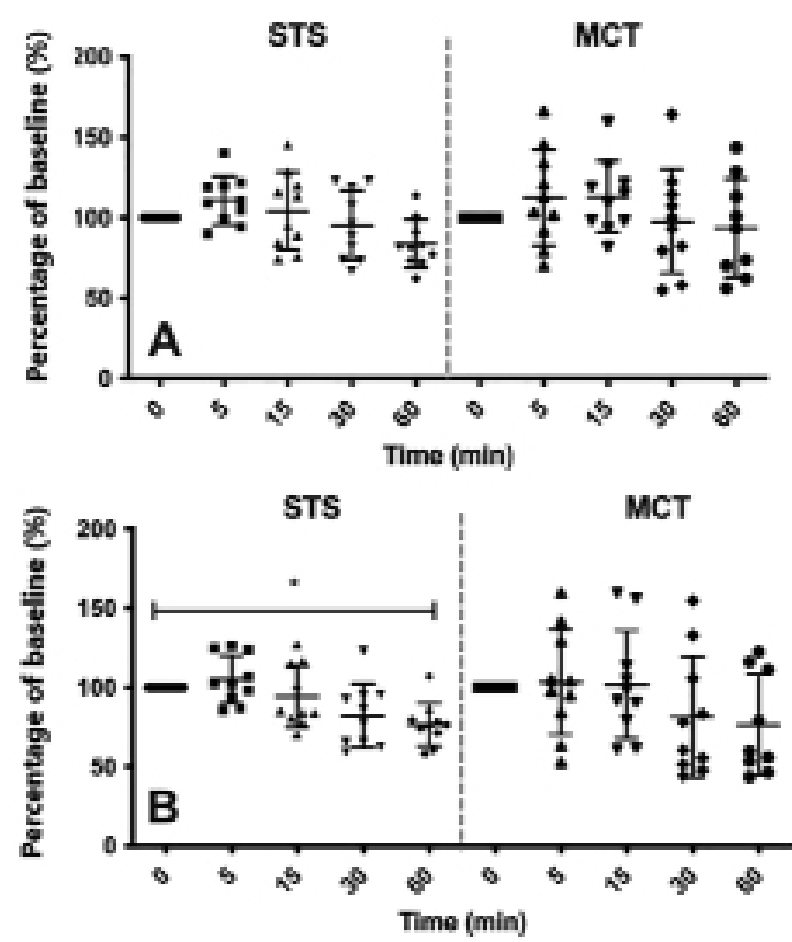

Figure 4-Changes in systolic (A) and diastolic (B) arterial blood pressure (percentage of baseline, with baseline considered as $100 \%$ ) from time 0 (before morphine administration) and $5,15,30$, and 60 minutes after morphine administration but prior to surgery. See Figure 2 for key.

crease in plasma histamine concentration after morphine administration, although this difference was not significant $(P=0.14)$.

Surgical manipulation of the MCT stimulated histamine release in $1 \mathrm{dog}$. By the 60-minute time point, surgery had been initiated in no dogs from the STS group and $1 \mathrm{dog}$ from MCT group. Data for this dog at 60 minutes were excluded for all calculations because of the possibility that manipulation of the MCT induced release of histamine. In this dog, plasma histamine concentration increased to 


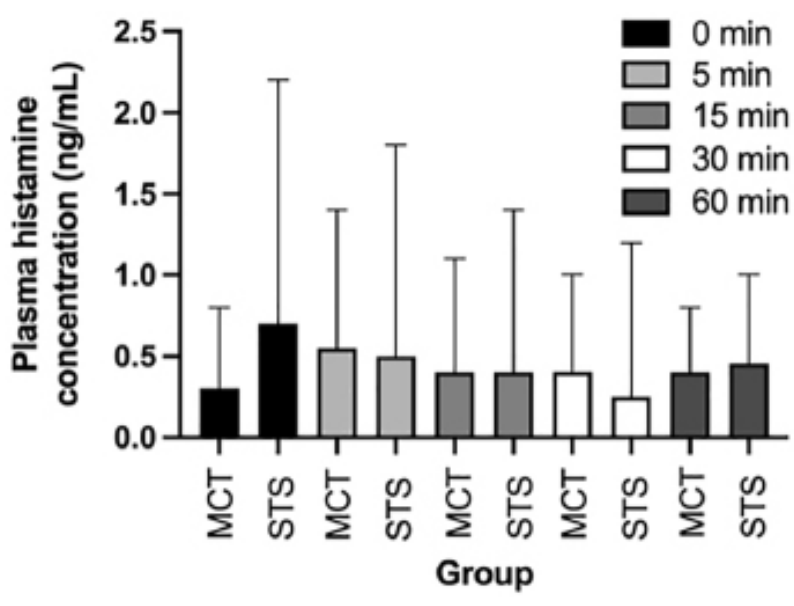

Figure 5-Median and $95 \% \mathrm{Cl}$ (whisker) plasma histamine concentrations before ( 0 minutes) and after $(5,15,30$, and 60 minutes) morphine administration but prior to surgery. Data at 60 minutes for I dog of the MCT group were excluded because surgery was initiated at this time point and surgical manipulation of the MCT may have induced release of histamine.

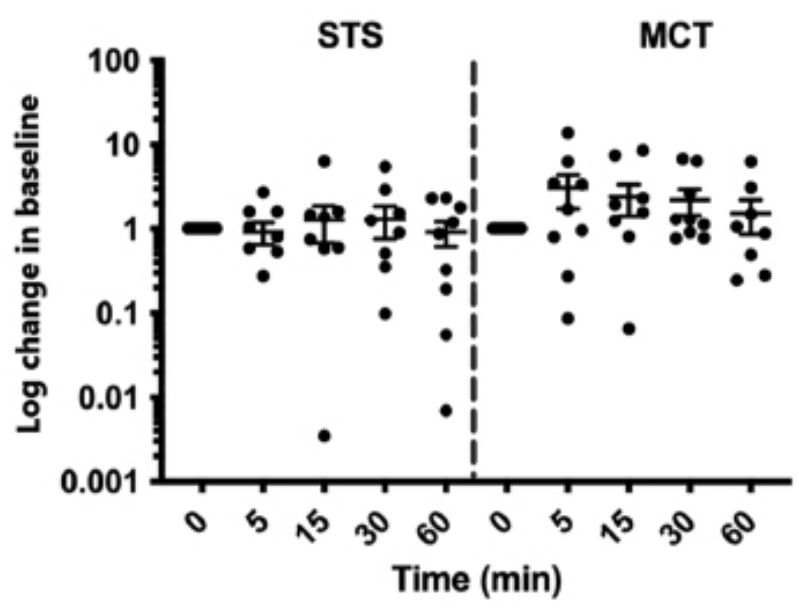

Figure 6-Log change in plasma histamine concentration from baseline (baseline considered as I at time 0 ) before morphine administration and $5,15,30$, and 60 minutes after morphine administration but prior to surgery. Data at 60 minutes for I dog of the MCT group were excluded because surgery was initiated at this time point and surgical manipulation of the MCT may have induced release of histamine. See Figure 2 for key.

$22.1 \mathrm{ng} / \mathrm{mL}$ from the pretreatment concentration of $0.1 \mathrm{ng} / \mathrm{mL}$.

No complications were observed in any dog during anesthesia, surgery, or the recovery period. All dogs were discharged from the hospital the day after surgery.

\section{Discussion}

In the present study, morphine did not induce histamine release from canine MCT cell lines, and morphine administered IM to dogs with STS or MCT did not induce significant changes in plasma histamine concentrations. Changes in hemodynamic parameters were as expected for morphine and were not suggestive of histamine release, MCT degranulation, or anaphylaxis. ${ }^{19-24}$

Dogs in the MCT group had lower baseline plasma histamine concentrations and were more likely to have a relative 3 -fold increase in plasma histamine concentrations after morphine administration, compared with concentrations for dogs in the STS group. However, baseline histamine concentrations in both groups were within the range for healthy dogs ( 0.1 to $1 \mathrm{ng} / \mathrm{mL})^{15,16,25}$ and healthy people. ${ }^{26-28}$ Furthermore, in the present study, plasma histamine concentrations did not reach $10 \mathrm{ng} / \mathrm{mL}$, a concentration expected to cause clinical signs induced by histamine. ${ }^{14,25}$ The relative increase in histamine concentration in the MCT group was possibly due to the lower baseline histamine concentration in this group than in the STS group.

Histamine release and high plasma histamine concentrations are considered the core for anaphylactic reactions in human and veterinary patients. ${ }^{23,24,29}$ Plasma histamine concentrations correlate with illness and death during the pathophysiologic processes that encompass systemic hypotension. ${ }^{23}$ In people, plasma histamine concentrations $>2 \mathrm{ng} / \mathrm{mL}$ can induce cardiovascular changes and subsequent clinical signs. ${ }^{26-28}$ For dogs, fewer studies exist and a variable range of plasma histamine concentrations have been described. In a previous study, ${ }^{25}$ a plasma histamine concentration of $300 \mathrm{ng} /$ $\mathrm{mL}$ was necessary to induce systemic hypotension in some dogs, although other dogs had localized flushing of the skin and mucus membranes. Other studies have shown little differences between species. For example, Owen et $\mathrm{al}^{30}$ reported that continuous infusion of histamine decreases arterial blood pressure in people, dogs, and cats in a similar dosedependent fashion. However, plasma histamine concentrations do not always correlate with systemic hypotension in people. ${ }^{31}$

In the present study, morphine was administered IM. In previous studies ${ }^{15,16,25,32,33}$ with dogs, significantly higher plasma histamine concentrations were reported following IV administration of morphine and higher doses of morphine. It was unknown whether IV (vs IM) administration or administration of morphine at higher doses (vs those used in the present study) would induce higher plasma histamine concentrations in the dogs of the present study. Only sedation was observed after morphine administration despite a study ${ }^{22}$ that indicates neuroexcitation in addition to sedation can occur. The difference among studies ${ }^{21,25,33-35}$ may be attributed to the dose, rate of administration, or route of administration.

The pathway by which morphine induces histamine release is not well understood. Reports ${ }^{9,11}$ indicate that it may not be mediated through agonism of $\mu$-opioid receptors or antagonism by naloxone. Thus, the manner by which histamine is released from MCTs may be more complex than expected. Hista- 
mine release may depend on the route and speed of morphine administration, morphine dose, and stage (tumor burden) of MCT. These aspects were not considered in the present study.

The greatest increase in plasma histamine concentration in the present study was noted for the dog that underwent surgical manipulation of its MCT 60 minutes after morphine administration. This finding was not surprising because MCT degranulation has been reported during tumor manipulation, with histamine release subsequently causing hypotension, coagulopathies, and local tumor edema and inflammation. ${ }^{18,19}$ Studies are necessary to better understand the risk of adverse effects secondary to histamine release from MCTs during surgery.

One important study limitation was that only 10 dogs with MCT and 2 canine MCT cell lines were evaluated. A larger population size is imperative to confirm that $0.5 \mathrm{mg}$ of morphine $/ \mathrm{kg}$, IM, does not induce significant histamine release in all or most dogs with MCT. Second, each dog had a relatively small-sized MCT; therefore, the effect morphine has on larger, more aggressive, or disseminated MCTs is unknown. Therefore, the results of the present study were considered preliminary. Third, blood samples were obtained from peripheral veins, and samples obtained from peripheral veins are not considered as the optimal sample type to determine plasma histamine concentrations. ${ }^{15,36}$ Fourth, an ELISA was used to determine histamine concentrations, and although it is commonly used, it may have suboptimal sensitivity, compared with other assays. ${ }^{15,36}$ Fifth, plasma histamine concentrations were determined 5, 15, 30, and 60 minutes following IM administration of morphine. Histamine concentrations could have differed at other time points. Lastly, only morphine was evaluated, such that additional studies are necessary to determine histamine concentrations after exposure to other opioids.

In conclusion, no significant changes in plasma histamine concentrations and hemodynamic parameters were observed in dogs with STS or MCT after IM administration of morphine. Rather, hemodynamic changes in both groups were attributed to morphineinduced sedation. These preliminary results suggested that morphine may be used safely in some dogs with MCT.

\section{Acknowledgments}

Funded by the Young Investigator Award program, College of Veterinary Medicine and Biomedical Sciences, Colorado State University.

The CR and BR cell lines used in the study were provided by Dr. Warren Gold, University of California-San Francisco, San Francisco, California.

The authors declare that there were no conflicts of interest.

The authors thank Barbara Rose for technical assistance.

\section{References}

1. Bostock DE. Neoplasms of the skin and subcutaneous tissues in dogs and cats. Br Vet J. 1986;142(1):1-19.
2. Brodey RS. Canine and feline neoplasia. Adv Vet Sci Comp Med. 1970;14:309-354

3. Lemke KA, Creighton CM. Analgesia for anesthetized patients. Top Companion Anim Med. 2010;25(2):70-82.

4. Berry SH. Analgesia in the perioperative period. Vet Clin North Am Small Anim Pract. 2015;45(5):1013-1027.

5. Steffey EP, Eisele JH, Baggot JD, Woliner MJ, Jarvis KA, Elliot AR. Influence of inhaled anesthetics on the pharmacokinetics and pharmacodynamics of morphine. Anesth Analg. 1993;77(2):346-351.

6. Muir WW III, Wiese AJ, March PA. Effects of morphine, lidocaine, ketamine, and morphine-lidocaine-ketamine drug combination on minimum alveolar concentration in dogs anesthetized with isoflurane. Am J Vet Res. 2003;64(9):11551160 .

7. Dyson DH. Perioperative pain management in veterinary patients. Vet Clin North Am Small Anim Pract. 2008;38(6):1309-1327.

8. Kongara K, Chambers JP, Johnson CB. Effects of tramadol, morphine or their combination in dogs undergoing ovariohysterectomy on peri-operative electroencephalographic responses and post-operative pain. N Z Vet J. 2012;60(2):129135.

9. Hermens JM, Ebertz JM, Hanifin JM, Hirshman CA. Comparison of histamine release in human skin mast cells induced by morphine, fentanyl, and oxymorphone. Anestbesiology. 1985;62(2):124-129.

10. Barke KE, Hough LB. Opiates, mast cells and histamine release. Life Sci. 1993;53(18):1391-1399.

11. Blunk JA, Schmelz M, Zeck S, Skov P, Likar R, Kopper W. Opioid-induced mast cell activation and vascular responses is not mediated by $\mu$-opioid receptors: an in vivo microdialysis study in human skin. Anesth Analg. 2004;98(2):364-370.

12. O'Donoghue LE, Rivest JP, Duval DL. Polymerase chain reaction-based species verification and microsatellite analysis for canine cell line validation. J Vet Diagn Invest. 2011;23(4):780-785.

13. Morel A, Darmon M, Delaage M. An immunoenzymoassay for histamine. Agents Actions. 1990;30(1-2):291-293.

14. Ishiguro $\mathrm{T}$, Kadosawa $\mathrm{T}$, Takagi $\mathrm{S}$, et al. Relationship of disease progression and plasma histamine concentrations in 11 dogs with mast cell tumors. J Vet Intern Med. 2003;17(2):194-198.

15. Guedes AG, Rudé EP, Rider MA. Evaluation of histamine release during constant rate infusion of morphine in dogs. Vet Anaesth Analg. 2006;33(1):28-35.

16. Robinson EP, Faggella AM, Henry DP, Russell WL. Comparison of histamine release induced by morphine and oxymorphone administration in dogs. Am J Vet Res. 1988;49(10):1699-1701.

17. Inference for means: comparing two independent samples. Accessed January 1, 2017. https://www.stat.ubc.ca/ rollin/ stats/ssize/n2.html

18. Moriello KA, Eicker SW. Influence of sedative and anesthetic agents on intradermal skin test reactions in dogs. Am J Vet Res. 1991;52(9):1484-1488.

19. Thamm DH, Vail DM. Mast cell tumors. In: Withrow SJ, MacEwen EG, eds. Small Animal Clinical Oncology. 3rd ed. WB Saunders; 2001:261-282.

20. London CA, Seguin B. Mast cell tumors in the dog. Vet Clin North Am Small Anim Pract. 2003;33(3):473-489.

21. Maiante AA, Teixeira Neto FJ, Corrente JE, Pedroso CEBP. Comparison of the cardio-respiratory effects of methadone and morphine in conscious dogs. J Vet Pharmacol Ther. 2009;32(4):317-328.

22. Monteiro ER, Rodrigues A, Assis HM, Campagnol D, Quitzan JG. Comparative study on the sedative effects of morphine, methadone, butorphanol or tramadol, in combination with acepromazine, in dogs. Vet Anaesth Analg. 2009;36(1):25-33.

23. Peters LJ, Kovacic JP. Histamine: metabolism, physiology, and pathophysiology with applications in veterinary medicine. J Vet Emerg Crit Care (San Antonio). 2009;19(4):311328. 
24. Shmuel DL, Cortes Y. Anaphylaxis in dogs and cats. $J$ Vet Emerg Crit Care (San Antonio). 2013;23(4):377-394.

25. Guedes AG, Papich MG, Rude EP, Rider MA. Comparison of plasma histamine levels after intravenous administration of hydromorphone and morphine in dogs. $J$ Vet Pharmacol Ther. 2007;30(6):516-522.

26. Lorenz W, Doenicke A, Schöning B, Ohmann C, Grote B, Neugebauer E. Definition and classification of the histamine release response to drugs in anaesthesia and surgery studies in the conscious human subject. Klin Wochenschr. 1982;60(17):896-913.

27. Duda D, Lorenz W, Menke H, et al. Histamine release during induction of anaesthesia and preparation for operating in patients undergoing general surgery: incidence and clinically severe cases. Agents Actions. 1992;36:C149C154.

28. Moss J. The impact of histamine research on clinical anesthesia and surgery. Agents Actions. 1992;36:C135-C148.

29. White MV. The role of histamine in allergic diseases. $J$ Allergy Clin Immunol. 1990;86(4 pt 2):599-605.

30. Owen DA, Harvey CA, Boyce MJ. Effects of histamine on the circulatory system. Klin Wochenschr. 1982;60(17):972-977.
31. Hirshman CA, Downes H, Butler S. Relevance of plasma histamine levels to hypotension. Anesthesiology. 1982;57(5):424-426

32. Muldoon SM, Donlon MA, Todd R, Helgeson EA, Freas W. Plasma histamine and hemodynamic responses following administration of nalbuphine and morphine. Agents Actions. 1984;15(3-4):229-234.

33. Thompson WL, Walton RP. Elevation of plasma histamine levels in the dog following administration of muscle relaxants, opiates, and macromolecular polymers. J Pharmacol Exp Ther. 1964;143:131-136.

34. Akcasu A, Unna KR. The role of mast cell disruption in the acute manifestations of the intravenous injection of morphine in dogs. Eur J Pharmacol. 1970;13(1):103-107.

35. KuKanich B, Lascelles BD, Papich MG. Pharmacokinetics of morphine and plasma concentrations of morphine-6-glucuronide following morphine administration to dogs. $J$ Vet Pharmacol Ther. 2005;28(4):371-376.

36. Beaven MA, Robinson-White A, Roderick NB, Kauffman GL. The demonstration of histamine release in clinical conditions: a review of past and present assay procedures. Klin Wochenschr. 1982;60(17):873-881. 